\title{
Acute Bacterial Infection in Kwashiorkor and Marasmus
}

\author{
IAN PHILLIPS,* M.A., M.D. ; BRIAN WHARTON, $\dagger$ M.B., M.R.C.P., M.R.C.P.ED., D.C.H.
}

"God cast down on them great tribulation, famine, and pestilence: the people perished." So Hesiod (c. 700 B.C.) described the association between famine and pestilence, and they have been firmly coupled in men's minds at least since that time. McCance (1951) has reviewed the historical association.

Children with kwashiorkor or nutritional marasmus often have acute bacterial infections. This has been established mainly by post-mortem surveys. Campbell (1956) found at necropsy microscopical evidence of pyaemic abscesses or bronchopneumonia in the lungs of 31 out of 40 malnourished children in Cape Town, and another six had evidence of renal infection. Renal lesions, many of them infective, were also found in two-thirds of a Jamaican series (Stirling, 1962), and Brown (1965) found a $45 \%$ incidence of bronchopneumonia among malnourished infants in a survey of all paediatric necropsies performed over a 12-year period in Mulago Hospital, Kampala. In Cape Town two clinical studies with bacteriological support attributed many of the deaths to infection of the gut and to generalized septicaemias (Smythe, 1958 ; Smythe an'1 Campbell, 1959). Usually, interest has been centred on one or more particular systems, and few attempts have been made to define the general pattern of bacterial infection.

Since it has been generally assumed that acute bacterial infection is common and serious, antibiotics have often been advised in the treatment of all cases of kwashiorkor and marasmus; but there is little agreement on the most suitable regimen. Penicillin is widely used (Béhar, Viteri, and Scrimshaw, 1957 ; Piburn, 1960; de Silva, 1964), sometimes with streptomycin (Dean and Swanne, 1963) or sulphadiazine (Hansen, 1961). Tetracycline is favoured in Jamaica (Garrow, Picou, and Waterlow, 1962), and Dean (1965) often used chloramphenical. The studies in Cape Town (Smythe, 1958) led to the use of a combination of chloramphenicol, neomycin, and nystatin, sometimes followed by penicillin and streptomycin and later by yoghurt.

During most of 1966 all children admitted to the Medical Research Council Infantile Malnutrition Research Unit, Kampala, received a five-day course of penicillin. Despite this, pyrexias often of unknown origin were common, tetracycline had frequently to be given later to control chest infections, and a few of the children showed signs of bacteraemic shock (Wharton, 1966). Finally, the records of the unit showed that, despite all these antibiotics, bronchopneumonia was commonly found at necropsy (Dean, 1965).

These clinical difficulties and the lack of agreement on therapy led us to study the pattern of acute bacterial infection in malnourished children in Kampala.

\section{Patients and Methods}

Seventy-five children (63 with kwashiorkor and 12 with marasmus) admitted consecutively to this unit over a ninemonth period were studied. The policy was to admit, as beds became available, malnourished children who would otherwise have been admitted to Mulago Hospital. No attempt was made to study outpatients with milder malnutrition.

- Lecturer in Medical Microbiology, Medical School, Makerere University College, Kampala, Uganda

t Paediatrician, M.R.C. Infantile Malnutrition Research Unit, Kampala, Uganda.
Throat swabs and samples of urine and stools were collected from all the children on admission, and later as occasion called for them. Swabs were also taken from superficial ulcers, abscesses, and other possibly infected lesions. Blood was taken for culture in cases of suspected septicaemia, pyrexia without obvious cause, hypothermia, or unexplained clinical deterioration.

At the beginning of the survey the first sample of urine was collected in a stick-on bag (Great Ormond Street Hospital pattern) after the perineum had been cleaned. If bacteriological results suggested contamination a second specimen was collected in the same way, but if the result was still uncertain urine was obtained by suprapubic aspiration. This is a simple technique, giving unequivocal results in most instances (Newman, O'Neill, and Parker, 1967). We now use it for collecting the first specimen from many children, especially if the skin of the groins and perineum is ulcerated.

The diagnosis of chest infection was made if there was radiological support for the clinical diagnosis or if Mycobacterium tuberculosis was grown from laryngeal swabs or gastric washings.

Cultures were made on standard media. Blood was inoculated into two bottles of Liquoid (sodium polyanetholsulphonate) broth (one for aerobic, and one for anaerobic incubation) and into one bottle of bile salt broth.

\section{Resuits}

\section{Incidence and Pattern of Infection}

The clinical and bacteriological data on each child were assessed. Thirty-two children $(43 \%)$ were thought to be "infected" and 39 (52\%) were "non-infected." The remaining four were diagnosed clinically as having chest infection, but there was no radiological or bacteriological support for the diagnosis. Of the marasmic children five were infected and seven non-infected.

The pattern of infection in the 32 children is shown in Table I. As some children had infections of more than one site the total of these is greater than 32. The most important "overlap" was in four children who had gut infections complicated by septicaemia.

In 21 of the 39 children thought to be non-infected no pathogens were demonstrated in any samples examined. The rest had a variety of minor infections-for example, of the

TABLB I.-Sites of Infection in 32 Infected Chlldren

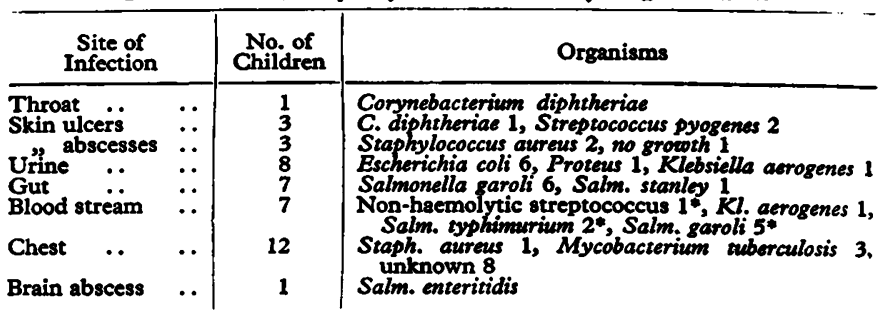

- Note: one child with sickle-csll anaemia had a septicaemia three times (non haemolytic streptococcus, Salm. typhimurium, Salm. garoli). 
skin (seven children, two with Streptococcus pyogenes) and of the upper respiratory tract (three children). There were also 11 "carriers" of Str. pyogenes, this organism being usually isolated from skin ulcers which showed no clinical sign of infection. Two more children in the non-infected group were faecal carriers of gut pathogens.

\section{Associated Features and Sequelae}

There were no significant differences between the infected. and non-infected children as regards age, sex, anthropometry, urinary hydroxyproline indices, concentrations in the serum of protein and electrolytes, or in their amino-acid ratios.

Hypothermia.-Ten of the infected children had rectal temperatures of less than $96^{\circ} \mathrm{F}$. $\left(35.6^{\circ} \mathrm{C}\right.$.) against only two of the non-infected children $(P<0.05)$. The former tended to be imall, thin, and wasted, characteristics already known to predispose to hypothermia in malnourished infants (Brenton, Brown, and Wharton, 1967), but three of the infected children who became cold showed none of these anthropometric stigmata and had not been regarded as likely to get cold.

Anaemia.-Table II shows the relation to anaemia (haemoglobin less than $10 \mathrm{~g} . / 100 \mathrm{ml}$.) of infection, parasitic infestation, and sickling. There was a progressive decrease in the incidence of anaemia from the group of children who had both infection and infestation or sickling, to the group who had none of these $(P<0.02)$. It appears that bacterial infection does contribute to the anaemia found in malnutrition, though its effect in Kampala is small compared with that of infestation or sickling. The haemoglobin level of most children fell during the first few days of treatment. The mean fall in the non-infected children was $0.8 \mathrm{~g} . / 100 \mathrm{ml}$., and in the infected group, after excluding those with septicaemia, it was $0.7 \mathrm{~g} . / 100 \mathrm{ml}$. The children with septicaemia showed considerably greater falls in hremoglobins, their mean fall being $2.3 \mathrm{~g} . / 100 \mathrm{ml}$. $(P<0.001)$. Septicaemia therefore caused a rapid fall in the haemoglobin concentration.

TABLE II.-Relation of Infection, Infestation, and Sickling to Anaemia in 69 Malnourished Children (2 Died Before the Haemoglobin was Determined)

\begin{tabular}{|c|c|c|c|c|}
\hline \multirow{2}{*}{$\begin{array}{l}\begin{array}{l}\text { Hookworm, malaria, } \\
\text { sictling }\end{array} \\
\text { Becterial infection }\end{array}$} & \multicolumn{2}{|c|}{ Present } & \multicolumn{2}{|c|}{ Absent } \\
\hline & Yes & No & Yes & No \\
\hline Total ... & 15 & 13 & 15 & 26 \\
\hline $\begin{array}{l}\text { No. with haemaglobir } \\
\text { below } 10 \mathrm{~g} / 100 \mathrm{~m} \text {. }\end{array}$ & $13(87 \%)$ & $9(69 \%)$ & $7(47 \%)$ & $10(40 \%)$ \\
\hline
\end{tabular}

Diarrhoea.-Infection other than enteritis did not increase the prevalence of diarrhoea. However, in children with sugar intolerance the presence of a non-enteric infection was associated with greater severity of diarrhoea. Thus seven children who had sugar intolerance and a systemic infection passed an average of 20 stools during the first five days after admission, while eight children with sugar intolerance but without systemic infection passed 11 stools.

Mortality.-Seven of the 32 infected children died (22\%) and two of the 39 non-infected children (5\%), an overall mortality of $13 \%$. In four of the infected children septicaemia had been demonstrated during life. Necropsy was performed on two of these and showed a small pericardial effusion in one. In another child urinary infection was diagnosed, but 12 hours after admission he died and extensive myocardial changes were found at necropsy. Septicaemia was suspected in another child only two hours before death; the blood culture was sterile, but pyelonephritis and a salmonella brain abscess were found at necropsy. The seventh child had, clinically, extensive bronchopneumonia.

\section{Diecuscion}

This study confirms the serious results of bacterial infection in malnourished children and shows that nearly half of those in this series had an infection for which antibiotics were clearly indicated. The remainder had nothing but trivial infection, and therefore in our opinion did not require antibiotics.

The most severe infections were due to Gram-negative organisms. Seven $(9 \%)$ had an enteric infection. They all had severe diarrhoea with marked sugar intolerance and four had septicaemia. Clinical management was therefore particularly difficult, especially as all strains of Salmonella garoli were resistant to chloramphenicol, ampicillin, streptomycin, and tetracycline. Another three $(4 \%)$ had a Gram-negative septicaemia without a demonstrated focus of infection. In all but two of the attacks the organism causing the septicaemia was a salmonella. Smythe and Campbell (1959) found salmonella septicaemia in six of the 105 children they studied, but also found an equal incidence of septicaemia due to gut commensals. Because of this study they suggested that the mechanisms preventing invasion by organisms from the gut-that is, the gut wall-and the properdin mechanism might be defective. Though this seems a reasonable argument, our experience would not support such a nonspecific defect, since salmonellae far outnumbered other organisms. The similarity between this experience and that with salmonella septicaemias which may complicate sickle-cell anaemia invites speculation.

Urinary infection was suspected clinically in only one child but was common enough to justify a careful examination of the urine in each child. Suprapubic aspiration was particularly valuable in establishing the diagnosis. This supports the necropsy findings of Stirling (1962) in Jamaica and Campbell (1956) in South Africa. Previously it had not been regarded as a problem in Kampala (Dean, 1965). Surprisingly enough no child with a urinary infection had a septicaemia. The serum potassium levels were no lower than those in children without urinary infection.

Gram-positive organisms were isolated only from the throat and the skin. Though there were three carriers, Str. pyogenes did not appear to be a cause of throat infections. While severe enough to warrant antibiotic therapy in only two children, streptococcal infection of the skin was common, and this may account for the raised antistreptolysin titres found in these children (Wharton, Balmer, Somers, and Templeton, 1967). It may also explain the paradox of a high incidence of rheumatic disease but a low incidence of streptococcal lesions at necropsy (Davies, 1948). It is of interest that virulent C. diphtheriae was isolated from a skin ulcer of one child.

Bacteriological support for the clinical diagnosis of a chest infection in children is rarely forthcoming. In this series Staph. aureus was isolated in large amounts from a sample of sputum in one child and was thought to be the cause of the child's pneumonia. We had hoped that throat swabs would help, but potential pathogens-Str. pmeumoniae, Staph. aureus, Pseudomonas aeruginosa, and coliforms-were isolated with equal frequency from those with and without chest infections. The high incidence of coliforms, usually Klebsiella aerogenes, in throat swabs is puzzling. Such organisms were much less common in the throats of a group of children attending an up-country clinic and a clinic in Kampala. Possibly antibiotics may have been given elsewhere before the children were admitted to this unit. Whatever the explanation, the organisms gave rise to no obvious harmful effects.

The results show that no single antibiotic would have provided universal cover. Penicillin would have been appropriate for the Str. pyogenes, C. diphtheriae, and perhaps some of the chest infections, but these were only a small proportion of the whole. Tetracycline would have covered all of them except the Salm. garoli, Proteus, and some strains of Staph. aureus. In Uganda, therefore, the routine administration of penicillin 
to all children with kwashiorkor is of doubtful value. A routine antibiotic such as tetracycline might be used, but since half of the children had no infection, and antibiotics may have serious side-effects, and since, moreover, it is difficult to devise a universal "umbrella," the value of routine antibiotic regimens is questionable.

Bacteriological evidence of infection should always be sought before antibiotics are prescribed, and we believe that the routine use of antibiotics in kwashiorkor may lead to a false sense of security and to diagnostic and therapeutic dilemmas.

However, bacteriological services are rarely available where kwashiorkor abounds, and therefore we make the following suggestions. Urine should be examined for pus cells. Pyuria should be confirmed by examination of a suprapubic sample where possible. Antibiotics should be prescribed only if there is some clinical indication of a particular infection-for example, of the skin, chest, throat, or blood stream. Diarrhoea is only occasionally due to a specific organism. Since it is usually impossible to distinguish clinically between infective and non-infective diarrhoea, a working rule might be to give antibiotics to those children with particularly severe diarrhoea (say more than six stools a day) or in whom a complicating septicaemia is suspected because of a high pyrexia or hypothermia, a "soft" spleen, a rapidly falling haemoglobin, or "warm hypotension" in an already very sick child.

\section{Summary}

About half the children admitted to this unit with severe malnutrition had an acute bacterial infection.

Gram-negative infections of the urinary tract, or gut, and septicaemia were particularly troublesome, while Gram-positive infections gave less cause for concern. The cause of most of the chest infections remains unknown.

Penicillin would have been appropriate for only a few infections, and if a routine antibiotic is thought to be necessary tetracycline would be better. There are, however, pertinent arguments against the routine use of antibiotics, and bacteriological evidence of infection should be sought wherever possible before the antibiotics are prescribed.

If bacteriological services are not available antibiotics should be given only if there is clinical indication of a particular infection-for example, of the skin, chest, throat, gut or blood stream.

Mr. R. Fernandes gave valuable technical assistance, and Dr. H. C. Chapman and Sisters A. Court, E. Strange, C. Roberts, G. Crewe, M. Hood, and S. Mukasa helped in the care of the children and the collection of specimens. We are grateful to all of them, and to Professor R. A. McCance and Professor R. Blowers for their advice.

Requests for reprints should be addressed to M.R.C. Infantile Malnutrition Research Unit, P.O. Box 7051, Kampala, Uganda.

\section{REFERENCES}

Béhar, M., Viteri, F., and Scrimshaw, N. S. (1957), Amer. F. clin. Nutr., $5,506$.

Brenton, D. P., Brown, R. E., and Wharton, B. A. (1967). Lancet, 1, 410.

Brown, R. E. (1965). Trop. geogr. Med., 17, 289.

Campbell, J. A. H. (1956). Arch. Dis. Childh., 31, 310

Campbell, J. A. H. (1956). Arch. Dis. Childh, 31,

Dean, R. F. A. (1965). In Recent Advances of Paediatrics, edited by D. Gairdner, 3rd ed., p. 234 . London.

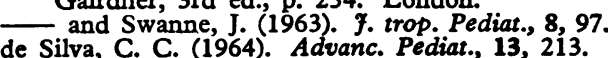

Garrow, J. S., Picou, D., and Waterlow, J. C. (1962). West Indian med. 7., 11, 217.

Hansen, J. D. L. (1961). In Recent Advances in Human Nutrition, edited by J. F. Brock, p. 267 . London.

Hesiod (c. 700 B.c.). Works and Days, edited by T. A. Sinclair, 1932. London.

McCance, R. A. (1951). In Spec. Rep. Ser. Med. Res. Counc. (Lond.), No. 275 , p. 21.

Newman, C. G. H., O'Neill, P., and Parker, A. (1967). Brit. med. J., 2, 277.

Piburn, M. F. (1960). Cent. Afr. 7. Med., 6, 149.

Smythe, P. M. (1958). Lancet, 2, 724.

and Campbell, J. A. H. (1959). S. Afr. med. 7. 33, 777

Stirling, G. A. (1962). Arch. Dis. Childh., 37, 378.

Wharton, B. A. (1966). E. Afr. med. \$., 43, 570.

Wharton, B. A., Balmer, S., Somers, K., and Templeton, A. C. (1967) In preparation.
* Senior Registrar, Medical Unit. St. Mary's Hospital, London W.2.

† Lecturer in Bacteriology, St. Mary's Hospital Medical School, London W.2. Present address : Department of Bacteriology, University of Liverpool, Liverpool 3. tation, and this is a report of our experience of peritoneal dialysis for periods of two to seven months.

\section{Patients and Methods}

Details of the 27 patients who received peritoneal dialysis for more than two months are shown in Table I. They were

TABle I.-Details of $2 ?$ Patients Receiving Prolonged Peritoneal Dialysis

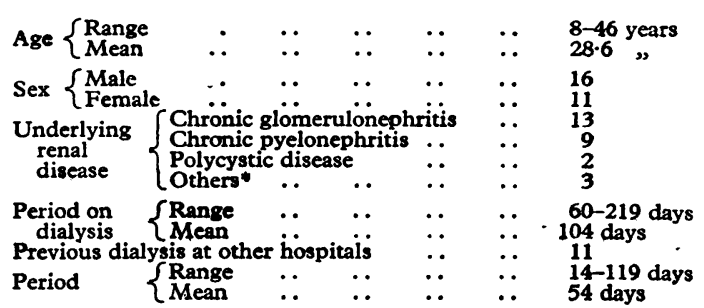
Acute glomerulonephritis 1, congenital hyperoxaluria 1, and primary hyper-
tensive nephrosclerosis 1. 